\title{
A perspectiva do professor pesquisador/reflexivo e a figura do Barão de Münchhausen
}

\author{
Kátia Augusta Curado Pinheiro Cordeiro da Silva \\ Universidade de Brasília
}

\section{Resumo}

Trata-se de uma pesquisa teórica que se orienta na perspectiva do materialismo histórico-dialético ao elencar categorias para análise que estruturam a produção teórica do professor reflexivo/pesquisador, neste caso são elas: relação teoria e prática, autonomia, emancipação, investigação-ação. A partir dessa análise, apresentamos cinco pressupostos que entendemos serem componentes da discussão da pesquisa do professor da educação básica. Finalizamos reafirmando a compreensão da educação como um campo de disputa hegemônica, e, portanto, pensar a pesquisa para a formação e atuação docente pode representar um processo de responsabilização ou de possibilidade emancipatória referendado na condição epistemológica e coletiva do ato de pesquisar.

Palavras-chave: Formação de professores. Professor reflexivo/pesquisador. Pesquisa. Trabalho docente. 


\section{The Researcher/reflective Teacher's Perspective and the "Baron of Munchhausen" Character}

This article presents a literature review guided by historical and dialectical materialism, in which are listed categories for analysis that structure the theoretical production of the reflective/researcher teacher; in this case, the relationship between theory and practice, autonomy, empowerment, and action research. Based on this analysis, we present five assumptions that we believe are components of the discussion about research by basic education teachers. We conclude by reaffirming the understanding of education as a battlefield for hegemony. Therefore, research for teacher education and work may represent a process of accountability or an emancipatory possibility, based on the epistemological and collective condition of the act of researching.

Keywords: Teacher education. Reflective/researcher teacher. Research. Teaching.

\section{La perspectiva del profesor investigador/reflexivo y la figura del Barón de Münchhausen}

Se trata de una investigación teórica orientada por la perspectiva del materialismo histórico y dialéctico presentando una lista de categorías de análisis que estructuran la producción teórica sobre el profesor reflexivo/investigador, que, en este caso, son la relación entre la teoría y la práctica; la autonomía; el empoderamiento y la investigación-acción. A partir de este análisis presentamos cinco supuestos que a nuestro entender son los componentes de la discusión sobre la investigación de los profesores de la educación básica. Se concluye reafirmando la comprensión de la educación como un campo de disputa hegemónico y, por lo tanto, la investigación sobre la formación y la acción de los profesores puede representar un proceso de responsabilidad o la posibilidad emancipadora, bajo la condición epistemológica y colectiva de las acciones investigativas.

Palabras-clave: Formación de profesores. Profesor reflexivo/investigador. Investigación. Enseñanza. 


\section{Introdução}

0 objeto do nosso estudo, a pesquisa do professor da educação básica, temse apresentado importante no âmbito da educação, especificamente na discussão sobre formação de professores. Segundo André (2005), é consensual na área a ideia de que a pesquisa é um elemento considerado essencial para a formação e atuação docente, além de estar presente na literatura e em textos oficiais importantes. Entretanto, a consensualidade não indica formas iguais de pensar a pesquisa do professor; pelo contrário, abriga diferentes visões de docência, pesquisa, trabalho docente e função social da escola e do profissional docente.

Uma das principais formas, podemos dizer, hegemônicas de pensar a pesquisa do professor da educação básica está inserida no movimento que tem sido mais comumente denominado de professor pesquisador e professor reflexivo, cuja referência, no nosso entendimento, é a pesquisa-ação'.

0 movimento de compreensão do que subjaz à perspectiva de formação via professor pesquisador/reflexivo que fazemos se justifica no fato de que, para compreender a concepção e prática de pesquisa dos professores da educação básica, necessitamos elucidar as concepções hegemônicas sobre a questão da pesquisa do professor da educação básica. Entendemos que o campo da formação inicial de professores ancora-se na perspectiva teórica do professor pesquisador/ reflexivo para discutir a pesquisa na formação e atuação dos professores, tendo como referência a abordagem qualitativa da pesquisa-ação - portanto a discussão da temática torna-se imprescindível.

Nesse sentindo, faz-se urgente compreender e revelar as implicações desse modelo de formação e pesquisa do professor. Foi traçada uma metodologia de trabalho que permitisse a coleta de informações sobre o objeto na perspectiva de estudo teórico, tendo como referências algumas categorias que compõem o ideário do professor reflexivo: relação teoria e prática, autonomia, emancipação, investigação-ação. A pesquisa utilizou da estratégia do estudo bibliográfico; portanto, este artigo é resultado da pesquisa teórica. Nesse sentido, o presente estudo teve como principal objetivo revelar a constituição do conceito de professor pesquisador/reflexivo, bem como dialogar criticamente com os autores que servem de referência para a discussão sobre a temática do professor pesquisador e do professor reflexivo no campo da formação de professores.

Podemos apontar três correntes que abordam a questão do professor pesquisador/reflexivo: uma, nos Estados Unidos, utiliza como ponto de partida os conceitos de Dewey (1933), da qual, hoje, as maiores expressões são Donald

1. Aqui usamos o termo pesquisa-ação porque entendemos que essa é uma das formas principais de pesquisa em que a teoria do professor pesquisador/reflexivo se baseia. 
Schön (2000) e Kenneth Zeichner (1993); a segunda, oriunda da Inglaterra, cujos representantes são Lawrence Stenhouse (1987 e 2003) e seu seguidor Jonh Elliot (1998), tem como matriz do pensamento as concepções de Kurt Lewin (1946); a terceira corrente de discussão tem como representantes Wifred Carr e Stephen Kemmis (2001), advindos da Austrália, que também partem das concepções de Kurt Lewin (1946).

As propostas agrupadas sob o nome de professor pesquisador/reflexivo, apesar das diferenças particulares, podem ser entendidas também como uma tendência na formação docente, que vem se tornando bastante hegemônica. Na relação entre estas propostas e na delimitação entre elas, as categorias lepistemologia da prática, relação teoria e prática, autonomia, emancipação, investigação-ação) que estruturam seus argumentos apresentam fortes afinidades, o que parece se impor como uma tendência ideológica ${ }^{2}$. Assim, iniciamos com a seguinte questão: $A$ concepção do professor pesquisador/reflexivo seria, portanto, ideal ou ideológica?

\section{Pressupostos teóricos-conceituais}

Para responder à questão elencada anteriormente, apresentamos a síntese dos principais pressupostos comuns que embasam a epistemologia da prática: a) o professor é o único responsável pelo ensino e pela sua prática; b) a ênfase da relação teoria e prática recai sobre a prática, e, como a escola é o contexto natural em que ocorre o trabalho do professor, ele deve falar, narrar apenas as questões desse local; cl é necessário uma ressignificação da prática pedagógica, pois o professor é um mediador do conhecimento e tem uma prática sempre complexa e imprevisível, e o conhecimento é visto como particularizado, comungando com uma perspectiva pós-moderna; d) a escolha do modelo pedagógico é mediada pelas necessidades imediatas do mundo do trabalho; el a pesquisa é vista como uma atitude investigativa, definida a partir da epistemologia da prática e da formação na ação.

O primeiro pressuposto - o professor é o único responsável pelo ensino e pela sua prática - mostra que as propostas de professor pesquisador aparecem encapsuladas na noção de indivíduo, de liberdade e autonomia. Reforçam, sistematicamente, a capacidade de escolha normativa dos indivíduos, de definição

2. Entendendo ideologia a partir de Gramsci como "uma concepção de mundo que se manifesta implicitamente na arte, no direito, nas atividades econômicas e em todas as manifestações da vida intelectual e coletiva" (1999, p.16). A questão é que a ideologia difundida nas camadas sociais dirigentes é evidentemente mais elaborada que os seus fragmentos encontrados na cultura popular. Na cúpula, a concepção de mundo é mais elaborada: a filosofia; nas classes populares, o folclore e por isso pode coerir em sua direção se tornando hegemônica. 
ou representação de situações problemas, e de geração de respostas criativas e adequadas. 0 destaque do professor como indivíduo autônomo em contexto de práticas imprevisíveis, incerteza, contingência ou indeterminação mostra-nos que se interpreta a história humana e da modernidade não a partir do modo de produção capitalista, mas, sim, de acordo com a emancipação do indivíduo.

Essa proposta parece retomar o referencial Kantiano da emancipação do indivíduo que pensa por si mesmo. Mesmo Zeichner (1993) e Carr e Kemmis (2001) salientam a importância da questão social, histórica e cultural, adotando o indivíduo como valor supremo, independente, autônomo e, por consequência, essencialmente não social (Renaut, 1988), aliada à perspectiva pós-moderna. A proposta apresenta uma epistemologia baseada em uma subjetividade que anula a realidade objetiva e sua tensão dialética com a realidade. Perguntamo-nos, junto com Freitas (2005, p. 92), “[...] até que ponto retornar ao subjetivismo não constitui uma maneira de ocultar o real, transferir a crise do capitalismo real para o âmbito pessoal e isentá-lo de suas responsabilidades pelas incertezas em que jogou boa parte da população mundial?".

$\mathrm{Na}$ formação de professores, a perspectiva individualista os coloca, a eles próprios, como responsáveis diretos para que a escola forme o homem do novo século, sendo sua responsabilidade o sucesso e principalmente o fracasso da empreitada. Autores como Schön (2000) e Perrenoud (2001) irão dirigir seus esforços no sentido de definir não só as competências e técnicas, mas principalmente o caminho para que o professor produza no seu cotidiano profissional as condições individuais e as oportunidades para um ensino eficiente. Nesse sentido, os professores foram desapropriados do discurso crítico e perderam o direito à indignação, e, se o fracasso é individual, equivale falar do seu fracasso pessoal, pois o indivíduo é ele.

Uma incorreta interpretação da pesquisa-ação pode responsabilizar o sujeito, no caso, o indivíduo (da ação, da pesquisa), pela mudança pretendida, o que é um equívoco, pois as ações individuais, principalmente as docentes, são limitadas, conforme as mediações e condições históricas, políticas, sociais e teóricas do momento.

Em sintonia com o atual momento da produção capitalista e da filosofia liberal, há, na formação do professor pesquisador/reflexivo, uma valorização da “liberdade de", mais individualista, que enfatiza a capacidade de realização pessoal, uma vez que o sofrimento causado pela sociedade desigual, que suga o máximo do homem, só pode ser amenizado se cairmos no indivíduo. Quando tomamos como base as perspectivas teóricas, é possível enunciar, como tese, que a proposta do professor pesquisador/reflexivo parece enfatizar a "liberdade de", embora coloque como proposta a "liberdade para". Trata-se de perguntar o que posso fazer lliberdade 
de) e quem tolhe o que faço (liberdade para).

A resposta para angústias e, consequentemente, para o trabalho alienado está apenas nas condições subjetivas, o que é um equívoco lógico e histórico, pois elas dependem também das condições efetivas de trabalho, que podem ou não auxiliar o professor na busca de relações mais conscientes com a atividade social que desenvolve ou mesmo contribuir para uma educação de mais qualidade. Portanto, a responsabilidade não pode ser colocada no professor, mas em um conjunto de condições e mediações, que são mascaradas ou ignoradas. Ao assumir a perspectiva individualista de formação, a proposta do professor pesquisador/reflexivo assume a posição ideológica hegemônica, apesar de conter o ideal humanista.

0 fracasso escolar e a necessidade de formar "novos cidadãos" para atuarem como trabalhadores e consumidores no atual estágio do capitalismo têm provocado um mal-estar crescente quanto à formação de professores, visto que "são os responsáveis pelo ensino e por sua prática". Isso tem levado, com muita frequência, à sustentação de posições que reivindicam o valor da prática como fonte de aprendizagem e o valor da reflexão sobre a prática como eixo do processo formativo. Aprender a partir da prática é uma expressão que tem ganhado consenso e com frequência se apresenta como verdade inquestionável, pois esse movimento estabeleceria uma relação entre teoria e prática. Desse raciocínio nasce o segundo pressuposto: a ênfase da relação teoria e prática deve recair sobre a prática.

Um primeiro olhar sobre a complexidade do problema, o que fomos fazendo ao longo do texto, mostra-nos um campo idealista e reducionista. Aprender a partir da prática é uma premissa importante e óbvia, mas tem muitas direções, e o perigo está em perder o sentido político da própria prática, uma vez que esta situa-se dentro de contextos institucionais políticos, sociais e éticos, por vezes vistos de forma fragmentada, com atores sociais que possuem concepções muito diversificadas acerca da aprendizagem, limitadas pelas condições de trabalho.

Além disso, a análise dos autores na epistemologia da prática apresenta uma identificação mais ou menos linear entre "atividade de prática" e "atividade de ensinar" e a concepção de aprendizagem estreitamente vinculada aos processos de aprender a ensinar, ou melhor, aprender a ensinar o aprender a aprender. Parece confuso, mas está se conformando à aprendizagem de professores e alunos e às necessidades básicas imediatas. Assim, a aprendizagem a partir da prática se mostra como um processo passivo de adaptação ao ritmo de aula, de pensar novas formas de ensinar ou resolver os problemas de aprendizagem, incluindo seus alunos no aprender a aprender. A criatividade fica por conta das "inovações" metodológicas los casos de pesquisa ou mesmo premiação de melhor professor apresentam as características de centrar na melhora da forma de 
ensinar a aprender).

Os problemas da racionalidade técnica e da dicotomia teoria e prática não são superados com uma simples mudança curricular na formação pela imersão e reflexão da prática. Pelo contrário, tudo isso pode reforçar uma racionalidade mecanicista e reprodutivista, reduzindo a ideia de reflexão e construção do conhecimento na ação. A imersão na prática não é suficiente para articular a unidade teoria e prática, é necessário reconstruir a experiência com marcos conceituais que orientem a ação, ou seja, é necessário que a formação permita a construção de significados para a reflexão e a ação. Sem uma matriz teórica clara, dotada de significados e de conteúdos interpretativos, a capacidade para produzir reflexão é limitada, apesar de sermos todos filósofos (Gramsci, 1999); podemos, em determinadas condições históricas, repetir, até mesmo de forma criativa, o movimento de adesão à massa, o que pode resultar numa situação catártica, dados os índices de insatisfação no trabalho docente (Zaragoza, 1999; Codo, 2002) e os difíceis problemas sociais que enfrentam.

A análise da noção de prática dos autores nos leva a afirmar que se trata de uma noção de prática limitada ao âmbito do saber fazer em sala de aula, ampliada no máximo à escola. Essa ênfase na prática apresenta uma visão empirista da prática como espaço do real, reduzindo o trabalho do professor; a técnica do saber intrumentalizado, agora mais flexível, criativa e autônoma, ou seja, um neotecnicismo (Freitas, 1998). Assim, a imersão na prática corre o risco de estimular um praticismo que consolide os rituais. Esse praticismo nos leva a questionar: é a recuperação da prática ou o recuo da teoria?

Reivindicamos uma valorização da prática como ponto de partida da reflexão, porém dentro de um movimento dialético que revele as contradições e mediações dessa prática, utilizando de conceitos e categorias teóricas e, principalmente, recuperando uma totalidade explicativa que proporcione um debate político, cultural e social da escola, dos alunos e principalmente do trabalho docente, tomando-o como princípio educativo, evitando, assim, um fazer adaptativo, no qual a relação teoria e prática se converta em praticismo.

Necessitamos compreender que o real não é uma presença objetiva monolítica, mas está fortemente determinado pela maneira que os sujeitos percebem e constroem a realidade, ou seja, a partir das suas relações objetivas e subjetivas, principalmente pelas relações de produção. A prática humana, e especificamente a prática educacional, é uma prática intencionalizada, ou seja, sua existência, sua construção, sua substancialidade se constituem exatamente pela condição de ser uma ação de intervenção humana e social; assim, é preciso ver as práticas dos sujeitos e grupos numa perspectiva de totalidade.

0 que estamos reivindicando é que, ao colocar a prática como objeto de pesquisa 
do professor, é necessário que ele a teorize como processo de mediação e de busca da unidade teoria e prática. Esse processo não pode acontecer na imediaticidade, com modelos predeterminados, nem por meio de teorias superficiais, uma vez que é o resultado de uma atividade histórica, atividade da qual a compreensão crítica de si mesmo é obtida, portanto, por meio de uma luta de hegemonias políticas, de direções contrastantes, primeiro no campo da ética, depois da política, atingindo finalmente uma elaboração superior da própria concepção do real. A consciência de fazer parte de uma determinada força hegemônica (isto é, consciência política) é a primeira fase de uma ulterior e progressiva autoconsciência, na qual teoria e prática finalmente se unificam.

Se coloca o problema de identificar teoria e prática, coloca-se neste sentido: de construir sobre uma determinada prática uma teoria, a qual, coincidindo e identificando-se com os elementos decisivos da própria prática, acelere o processo histórico do ato, tornando a prática mais homogênea, isto é, elevando-a à máxima potência; ou então, dada uma certa posição teórica, no sentido de organizar o elemento prático indispensável para que esta teoria seja colocada em ação. (Gramsci, 1999, p. 51)

A teoria possibilita, de modo indissociável, o conhecimento da realidade e o estabelecimento de finalidades para sua transformação. No entanto, para produzir tal transformação, não é suficiente a atividade teórica; é preciso atuar praticamente sobre a realidade, em que a principal forma de atuação humana é o trabalho, e, assim, por meio dele, pode-se articular teoria e prática. É importante enfatizar que a prática não se basta a si mesma; se isso acontece, fica situada passivamente numa atitude acrítica em relação a si mesma e perde sua capacidade transformadora, tornando-se aderência ${ }^{3}$ e, apesar de algumas inovações que possa apresentar na aparência, sua essência é de conservação do real. É na unidade teoria e prática que pode haver uma práxis transformadora da realidade. Se sobre o real deve-se elaborar uma teoria que seja capaz de acelerar seu devenir histórico, é porque cada indivíduo pode tornar-se intelectualmente melhor, mais qualificado, capaz de agir política e filosoficamente na esfera pública.

0 terceiro pressuposto na epistemologia da prática afirma ser necessária uma ressignificação da prática pedagógica, pois o professor é um mediador do conhecimento e tem uma prática sempre complexa e imprevisível, em que o

3. 0 termo aderência indica um movimento em que a lógica, a razão que impera, faz com que o sujeito não consiga se identificar num processo de semelhança e de diferença, pois identidade é dizer: "isto sou eu”, "isto não sou eu", ser capaz de se distinguir do outro, do objeto. Na aderência há apenas aceitação do que está posto, naquilo que se percebe e se busca a semelhança, o sujeito perde a autonomia. 
conhecimento é visto como particularizado, comungando com uma perspectiva pós-moderna. A ideia do professor como mediador assume o significado de que professor não fornece conhecimento, mas possibilita que o aluno consiga apreender os vários conhecimentos a partir de caminhos que vão sendo construídos com o auxílio do docente.

Essa ideia, presente em correntes de matrizes teóricas diversas, tem como objetivo central colocar a escola como instituição primordial para a construção da democracia ${ }^{4}$. Para tanto, seria (e será) necessário modificar o papel, diretivo ou autoritário, que o professor teria na educação "tradicional", pela mediação que gera acordos em termos de valores e de conhecimento. Observemos, para não pensarmos que estamos diante de uma peculiaridade da educação, que a "mediação" aparece hoje como recurso valioso de solução de conflitos.

Um dos possíveis efeitos dessa postura é provocar uma confusão entre conhecimento (conteúdo) e prática docente. A produção sobre o professor pesquisador/reflexivo, que apresenta como uma de suas perspectivas primordiais a ideia de que a atividade docente produz um novo conhecimento, confunde processo de aprendizagem com conteúdo a ser aprendido. Os professores aprendem cada vez mais como ensinar e sabem cada vez menos o que ensinar; a maneira como cada professor ensina tem sido colocada como um novo conhecimento. Teremos então a produção de um docente que se preocupa mais com sua performance e menos com o que diz. 0 professor, que deverá ensinar o aluno a "aprender a aprender", deverá também "aprender a aprender" durante a sua formação, por isso a categoria prático-reflexivo-pesquisador é usada com tanta propriedade. (Arce, 2001)

Outro efeito decorrente da ideia do professor como mediador é afirmar que sua prática está mais próxima do que faz o artesão ou o artista, uma vez que ela é sempre imprevisível e complexa, só na situação do artista e da criatividade se pode dar conta dessa prática. Essa perspectiva tem sido defendida pelas várias correntes que reiteram a ideia de que o professor, ao refletir sobre sua própria prática (o professor reflexivo), torna-se um artesão na medida em que cada ação é um produto único. Colocamos como tese que o papel docente, tal qual é definido pela literatura sobre o professor pesquisador e o professor reflexivo, está mais próximo do bricoleur nos termos entendidos por Schön (2000) e Perrenoud (2001), isto é, aquele que está apto a executar um grande número de tarefas diferentes, mas a regra de seu jogo é arranjar-se com os seus limites.

Nesses limites encontram-se também dados para o cientista na medida em

4. Princípio forte na produção de Dewey (1933), retomado neste momento via ideia de aprender a aprender, esboçado no construtivismo para o aluno e na proposta do professor pesquisador/ reflexivo para o professor. 
que tem que inventariar um conjunto predeterminado de conhecimentos teóricos e de meios técnicos. No entanto o que separa o cientista do bricoleur é que o primeiro opera por meio de conceitos (cujo estoque é ilimitado) e o segundo, por meio de signos (cujo estoque é limitado). 0 professor pesquisador/reflexivo, para se constituir artesão, terá que se valer tanto do conhecimento científico, quanto da atividade do bricoleur. Seria possível pensar que a perspectiva do bricoleur poderia se constituir em saída para a atuação docente?

Outro princípio básico da mediação e suas decorrências se apresenta com 0 suposto conceito de autonomia. 0 professor deve ser autônomo, como também o deve ser o trabalhador, fruto da terceira revolução industrial: flexível, criativo, rápido, capaz de refletir, tomar decisões, etc. 0 docente deve-se adequar aos novos tempos, formando-se nessa perspectiva, bem como aos novos "cidadãos". Enfim, o novo docente deve ser alguém que se compreenda ou, dizendo de outra forma, deve ser um aprendiz do (e no) seu próprio trabalho.

Essas ideias já engendradas pelo princípio de mediação e as decorrências que listamos são reforçadas pela emergência da memória docente e sua importância para a compreensão que esse profissional deve ter em relação a suas atitudes. É nesse sentido que se iniciam as pesquisas que procuram resgatar a incidência da memória docente (o seu passado), na sua atuação do presente. Reforça-se o papel da autonomia, assim como a negação da técnica e da ciência no modelo que preza a universalidade e, por vezes, faz da técnica lo professor pesquisador reflexivo, que pensa a prátical um sinônimo de ciência, epistemologia da prática. Parece, então, que o sistema se fecha em si mesmo e o professor torna-se sujeito de sua própria história por meio de uma dupla autonomia. Por um lado, ele constrói seu próprio caminho de aprendizagem e, por outro, implementa sua marca de pessoalidade e individualidade, pois o caminho é único e intransferível, na medida em que tem a marca do artista e de sua história individual; é uma volta em espiral em torno de si mesmo.

0 conceito de mediação da forma que é posto leva a entender que não é função do professor ensinar, apenas assegurar que seus alunos possam aprender a aprender num processo contínuo. 0 conhecimento também se torna particularizado de acordo com as teorias pós-modernas em detrimento da totalidade. Entretanto, reafirmamos a posição de que a função do trabalho docente é ensinar, ou seja, proporcionar ao aluno a apropriação do conhecimento já produzido pela humanidade e as condições intelectuais para produzir novos conhecimentos e nova direção para a humanidade. Isso requer uma mediação que não é um dom artístico, não é uma técnica, mas, sim, um saber profissional legitimado por conhecimentos conceituais e por uma visão historicizada desses conhecimentos, de si mesmo, da sociedade, de seus alunos e de sua profissão. 


\section{A escolha do modelo pedagógico é mediada pelas necessidades imediatas}

do mundo do trabalho. Esse pressuposto está contido não apenas nas propostas do professor reflexivo/pesquisador, mas na compreensão da própria função da escola, que abriga contraditoriamente a perspectiva da classe hegemônica, que busca formar o trabalhador na sociedade capitalista. Ao mesmo tempo, a perspectiva da classe trabalhadora e a função social da escola pública é "[...] buscar, na educação, conhecimentos e habilidades que permitam uma melhor compreensão da realidade e envolva a capacidade de fazer valer os próprios interesses econômicos, políticos e culturais." (Gryzybowski apud Frigotto, 1996, p. 26). Lembremos que a função social da escola na sociedade capitalista não é discutida nas diferentes propostas do professor reflexivo/pesquisador, apesar de Zeichner (1993) e Carr e Kemmis (2001) discutirem que a mudança ou justiça social se dará na escola e a partir dela.

0 conceito de transformação social está muito próximo da proposta liberal ou neoliberal, já que a transformação da sociedade prevista pela intervenção docente, no sentido do professor pesquisador reflexivo, é exequível nesses contextos. Ou seja, a defesa de uma sociedade mais justa, composta por indivíduos emancipados, com acesso aos bens de consumo, que respeitam as diferenças, não exige dela uma transformação estrutural. As novas propostas de formação parecem recusar a perspectiva coletivista e situar sua elaboração conforme o nível de cada docente, isto é, conforme a experiência pessoal de cada um. Passamos da transformação ${ }^{5}$ revolucionária para a mudança gradual da sociedade. Em síntese, defendem um conceito de transformação social que possa ser realizado na estrutura da sociedade capitalista, pois uma sociedade mais justa, mais equitativa, não significa ruptura com o modelo vigente.

Vejamos a seguinte comparação e questão: o trabalhador ou mesmo o empresário, que deve ser empreendedor, não é um "profissional reflexivo", aberto ao mundo, em contexto de incerteza e flexível, que deve entender o cliente e sua cultura? As interpretações e análises críticas sobre a formação docente costumam, como tendência, afirmar que ele é resultante da hegemonia do pensamento neoliberal que apresenta, como uma de suas características, a imposição, para a escola, de um modelo de gestão de conhecimento e de organização escolar muito próximo ao da empresa. De fato, a proposta do professor pesquisador/reflexivo parece apresentar pontos conceituais com os valores e diagnósticos presentes no empreendedorismo, na desregulação da economia e das relações de trabalho,

5. Um acesso mais igualitário à justiça, valioso em si mesmo, não significa uma transformação da sociedade sob o ponto de vista estrutural. Além disso, parece ser compatível com o capitalismo, e talvez até funcional sob determinadas circunstâncias, tanto quanto uma melhor distribuição da renda. 
na tarefa de inventar o próprio trabalho, a própria empresa, na personalização do consumo que substitui a imagem taylorista e fordista.

A reflexão, a criatividade e a autonomia do professor parecem estar próximas das características do trabalhador da fábrica, fazendo com que, cada vez mais, o professor perca a visão total de seu trabalho, conforme já apontamos no decorrer deste capítulo. Os argumentos construídos nas diferentes propostas do professor pesquisador/reflexivo que foram inseridos nas reformas educacionais, por sua vez orientadas pelas perspectivas neoliberais para a formação de professores, parece-nos apontarem para uma redução de custos, aumento do controle sobre a categoria profissional e uma crescente proletarização do trabalho docente, dando continuidade e força à culpabilização do professor pelas mazelas da educação.

0 quinto pressuposto faz com que retornemos à questão da pesquisa-ação, pois refere-se à concepção de pesquisa: a pesquisa é vista como uma atitude investigativa definida a partir da epistemologia da prática e da formação na ação. A maioria dos autores que compõem a matriz do pensamento professor pesquidador/reflexivo: Stenhouse (1987), Carr e Kemmis (2001), Elliot (1990) e Zeichner (1993), defendem a investigação do professor na perspectiva da pesquisaação; partem de um primeiro suporte que é a chamada atitude investigativa, que inclui a predisposição para examinar a sua própria prática de uma forma crítica e sistemática, ou seja, a disposição questionante e a manutenção do estado de dúvida. Essa atitude investigativa tanto é emotiva como cognitiva, sustentada por uma curiosidade, uma abertura para explorar diferentes fenômenos observados na sala de aula. É essa curiosidade que motiva o professor a agir como investigador.

Seguindo esse raciocínio, a investigação do professor distingue-se da investigação acadêmica por diferentes motivos. Em primeiro lugar porque as suas descobertas são imediatamente traduzidas na prática, no âmbito do mesmo contexto em que a investigação se realizou; portanto essa investigação emerge da prática e visa à prática. Em segundo, porque, ao se desenvolver no âmbito do trabalho do professor, desvincula-se da pesquisa da análise social mais ampla e do conhecimento científico acadêmico. Em terceiro, ao restringir a produção de conhecimentos ao conhecimento pedagógico, recusa-se a totalidade explicativa e se filia a uma concepção em que o senso comumb é emancipatório, pois sustenta que a ação do professor produz saberes que nada ficariam devendo aos conhecimentos obtidos por meio da pesquisa acadêmica. Assim, segundo autores que sustentam essa tese,

6. Quando se diz que um senso comum é emancipatório, trata-se de um conceito emergente, cuja proposta aponta para "um novo senso comum emancipatório", tornando difusos os limites entre senso comum e conhecimento científico. 
A prática do professor é resultado de outra teoria, quer seja ela reconhecida quer não. Os professores estão sempre a teorizar, à medida em que são confrontados com os vários problemas pedagógicos, tais como a diferença entre suas expectativas e os resultados. Na minha opinião, a teoria pessoal de um professor, a razão por que uma lição de leitura correu pior ou melhor do que o esperado, é tanto teoria como as grandes teorias geradas nas universidades sobre o ensino da leitura: ambas precisam ser avaliadas quanto à sua qualidade, mas ambas são teorias sobre a avaliação de objetivos educacionais. (Zeichner, 1993, p. 21)

É, portanto, uma “pesquisa voltada para a ação do professor o único capaz de examinar sua prática" (Zeichner; Liston, 1998 apud Geraldi, Fiorentini; Pereira, 1998, pp. 252-253). Só o detentor da prática, no caso o professor, está em condições de refletir sobre ela, constituindo uma ciência da prática, para dar respostas, que precisam ser imediatas. Nas investigações, essa ação produz saberes na reflexão que ocorre antes, durante e depois da ação do professor.

Não concordamos que essa prática seja pesquisa, pois, como bem situam os autores, refere-se a uma atitude investigativa, que resgata o subjetivo no sentido de escolha, de experimentação, sem análise nem construção de categorias centrais. Nessa forma de investigar a realidade, a primazia é do sujeito sobre o objeto, e é o sujeito que conhece e cria a realidade; portanto, é o sujeito que dá significado ao objeto. Rompe-se com a interação sujeito e objeto da visão dialética, bem como com sua historicidade.

Essa forma de investigação recusa a compreensão de que o senso comum, por sua condição histórica, é capaz de apreender apenas uma parte do fenômeno; afirma que esse é um tipo de conhecimento que advém da experiência e fornece a verdade. Defendemos, entretanto, que o senso comum é um saber não sistematizado, que orienta a vida cotidiana e que, portanto, é válido como formulação imediata. A ciência busca nesse saber informação para suas pesquisas e, muitas vezes, ele é informado pela ciência, porém há um limite histórico entre eles, pois o conhecimento sistematizado rompe com o senso comum e avança na sistematização dele, o que é um movimento necessário, pois é a superação do senso comum que permite revelar as contradições de uma realidade e buscar a formação de uma concepção coerente e unitária de sociedade.

$\mathrm{Na}$ ideia da prevalência da ação reflexiva e da valorização do senso comum como fonte fidedigna de conhecimento, que parece haver na proposta do professor reflexivo, está embutida a ideia de rechaçar a teoria como fonte de emancipação, de revelar a prática e, portanto, possibilitar a práxis. É importante afirmar que sem teoria não há práxis nem emancipação, o que pode ser o caminho mais difícil, mas não há outro, mesmo porque, "se a aparência fenomênica e a essência das 
coisas coincidissem diretamente, a ciência e a filosofia seriam inúteis". (Kosik, 1976, p. 13)

A pesquisa-ação nessa proposta trata a intervenção como se fosse uma categoria homogênea e a mudança, responsabilidade do professor. A pesquisaação é colocada como centro da solução de problemas, que são bem mais amplos, pois são históricos, políticos e sociais; parece-nos que fica no campo da retórica e da ação do professor, que pode ocorrer no voluntarismo frustrante.

$\mathrm{Na}$ sociedade de relações alienadas, algumas formas de pesquisa-ação e cotidianidade podem vir a ser uma ação dirigida por paradigmas que servem a determinados fins e valores. Isso acontece em decorrência do princípio que entende que o senso comum traduz a essência e que esta pode ser captada imediatamente. Assim, as pesquisas acabam por constatar representações, tomando-as como o concreto real.

Reiterou-se, neste trabalho, que a realidade não se dá a conhecer, isso pela condição histórica, cujas relações sociais e econômicas que a constituem não podem se mostrar de modo transparente, como se houvesse um véu atrapalhando a visão da essência, que, no caso, é a ideologia presente no imediato. Algumas formas de pesquisa-ação e de pesquisas do cotidiano podem acabar por contribuir para um círculo vicioso, pois

Ao invés de a pesquisa sobre a cotidianidade em educação contribuir para a superação das relações cotidianas alienadas na educação, tem ocorrido o inverso, isto é, por não compreender-se o que sejam as mediações entre educação, pesquisa e cotidianiedade, acaba-se absorvendo a estrutura alienada do cotidiano e utilizando-a como base metodológica da pesquisa. Assim a pesquisa volta ao cotidiano, legitimando sua estrutura alienada, em vez de contribuir para a superação dessa alienação. (Oliveira, 1996, p. 37)

É necessário admitir o cotidiano e a escola como locus de formação, dando voz àqueles que fazem a educação no país e que estão atuando diretamente na formação dos filhos da classe trabalhadora e, ao mesmo tempo, reconhecendo o trabalho desse profissional, possibilitando-lhe autonomia como sujeito capaz de produzir novos conhecimentos. Porém, não é com uma formação que limita o professor a pensar e agir em seu cotidiano que a educação se transformará como um todo.

Concordamos com Nóvoa (1997) que é necessário um investimento na pessoa do professor e na sua profissão, mas negamos a proposta de professor pesquisador/reflexivo, por entendermos que ela coloca tais categorias como adjetivas do professor. Na perspectiva de uma educação crítica e transformadora, 
reafirmamos a concepção sócio-histórica de educador definida pela Anfope (1992, $1994,1996,1998,2000,2002,2004,2006,2008,2012$ e 2014), que coloca como um de seus princípios orientadores a unidade teoria e prática, que implica a ênfase na pesquisa como meio de produção de conhecimento e intervenção na prática social, ou seja, defendemos a compreensão da pesquisa como uma forma de se relacionar com o conhecimento e com a realidade, entendida como ciência.

Como o sujeito irá desvelar a realidade, se o processo de alienação e reificação estão presentes? Pela práxis, perseguindo-a, pois a práxis do homem contém em si a própria realidade, e a busca da unidade não é um movimento natural, mas um esforço para, ao compreendê-la, poder transformar a realidade,

A práxis na sua essência e universalidade é a revelação do segredo do homem como ser ontocriativo, como ser que cria a realidade (humano-social) e que, portanto, compreende a realidade (humana e não humana, a realidade na sua totalidade). A práxis do homem não é atividade material contraposta à teoria; é determinação da existência humana como elaboração da realidade. (Kosik, 1976, p. 222)

Entendemos que a realidade é dialética e contraditória e, nas atuais condições, é caracterizada pela pseudoconcreticidade, na qual o fenômeno indica a essência e, ao mesmo tempo, a esconde (Kosik, 1976). Acredita-se que a pesquisa seja uma atividade que pode contribuir para a formação de sujeitos críticos e autônomos, capazes de intervenções transformadoras na realidade em que se inserem, desde que se recupere o concreto pensado, síntese de múltiplas determinações, compreendendo suas mediações; não é a pesquisa um mergulho na e pela realidade, mas uma busca de conhecê-la e transformá-la. Há o reconhecimento da potencialidade do professor para fazer pesquisas com a mediação teórica formulada como parte indispensável do processo; o limite é a condição histórica em que ele está inserido, bem como as condições materiais para a produção de pesquisa.

\section{A figura do Barão de Münchhausen}

Enfim, sejamos reflexivos! Deveríamos arrefecer o entusiasmo profético dos novos modos de ação, pois estamos correndo o risco de colocar velho vinho em odres novos. Sejamos prudentes, pois, de fato, se considerarmos a reflexão como componente geral de qualquer atividade, a proposta do professor pesquisador/ reflexivo só se sustenta ou na especificidade de sua reflexão - que, como vimos, é difícil definir e ainda esbarra na pseudoconcreticidade - ou na suposição de 
sua necessidade geral para todos, numa luta de elevação moral e intelectual da classe e da humanidade, o que tira a base da própria proposta, pois ela se torna indiferenciada.

Iniciamos com a seguinte questão: a concepção do professor pesquisador/ reflexivo seria, portanto, ideal ou ideológica? Talvez não tenhamos a resposta pois não há dicotomias, mas, à medida que nos afastamos da totalidade do trabalho docente, adjetivações e indicações de formação que buscam a saída na individualidade da prática docente podem contribuir com uma visão de culpabilização e responsabilização única do professor, e as saídas deixam de ser uma questão política e ética.

O componente da reflexão deve ser considerado indissociável do trabalho do professor, para o seu bom desempenho; entretanto, em termos gerais, a reflexão é constitutiva de qualquer atividade ou desempenho, a sua pertinência está associada à categoria humana e não apenas à do professor. Não podemos ter a reflexão e a pesquisa como categorias que separam e definem o profissional da educação. Aliás, não podemos determinar que o professor seja isso ou aquilo, mas apenas denunciar as suas condições e possibilidades, ou seja, não se podem cunhar categorias a priori, estas dependem da materialidade, pois, seguindo a premissa de Marx (1984), pode-se entender que as práticas é que fazem os professores e não os professores que fazem as práticas.

Caso tratemos da formação de professores tendo como referência o professor pesquisador/reflexivo, estaremos retomando a figura literária do “Barão de Münchhausen”, um homem tão autossuficiente que pode sair do pântano puxando seus próprios cabelos (Lowy, 1998). Nesse caso, o professor pode, sozinho, mergulhado no seu cotidiano por meio da reflexão, emergir dos problemas pedagógicos e sociais que acontecem em sua prática. Da mesma forma, os estudos sobre sua formação, encerrados em torno do desenvolvimento da profissão, trazem a ideia de que, agarrado no "cordão da sua bota" ou em seus "próprios cabelos", entendidos como refletir a prática e resolver as situações de conflito, conseguirá emergir da situação caótica em que se encontra a educação, sua profissão e a humanidade. Essa síntese e metáfora só é possível articulada às categorias de análise apresentadas anteriormente. A crítica refere que há questões na escola e no trabalho docente que ultrapassam a prática pedagógica e sua investigação, mas remetem a perspectivas estruturais em que as saídas são coletivas e referentes a um bloco da relação estrutura e superestrutura.

Essa perspectiva assume uma modalidade de pesquisa-ação, que passa a ser vista como meio de pensar a formação e o currículo, ou seja, passa a ser concebida como modelo de formação pesquisador/reflexivo, que deverá concentrar seu foco de análise no processo de aprendizagem - aparentemente compreendida como 
construção do conhecimento. De acordo com Duarte (2004), além de evidenciarem a pesquisa-ação como condição reflexiva do professor, tais teorias parecem alicerçar-se no ideário pós-moderno, reforçando a valorização do conhecimento produzido no cotidiano do professor, ou seja, o conhecimento advindo de sua prática, o que, no nosso entendimento, fragiliza o trabalho docente que está imerso em uma totalidade que vai além do cotidiano escolar.

Quando falamos em formação de professores e especificamente na possibilidade da pesquisa do professor da educação básica, temos como referência a perspectiva de atuação profissional marcada pela leitura marxista da realidade, dialogando com autores como: Gramsci (1978), Vygotsky (1991) e Manacorda (2000), bem como com professores e pesquisadores nacionais que produzem conhecimentos, portanto, ferramentas para a formação e a pesquisa do professor nessa linha.

Nesta produção, a função docente tem como tarefa primordial compreender as dimensões pedagógicas das relações sociais, bem como suas formas de realização por meio de diferentes práticas institucionais e não institucionais que produzem o conhecimento pedagógico, utilizando-as na complexa relação de mediar e transformar os saberes produzidos historicamente a favor da emancipação humana. Para realizá-la com competência, o professor deverá apropriar-se das diferentes formas de interpretação da realidade, que se constituem em objeto de vários campos de conhecimento, mas isso é insuficiente para sua atuação. Utilizando-se dessas ferramentas, precisa construir categorias de análise, a partir de uma síntese que lhe permita dialeticamente compreender as concepções e intervir nas práticas educativas no sentido de transformação da realidade.

\section{Referências}

ANDRÉ M. (org.) O Papel da pesquisa na formação e na prática dos professores. 4 ed. Campinas: Papirus, 2005.

ANFOPE. Documentos Finais dos V, VI, VII, VIII, IX, X, XI, XII, XII, XIV Encontros Nacionais da Associação Nacional pela Formação dos Profissionais da Educação. Brasília, de 1990 a 2014.

ARCE, Alessandra. Compre o Kit neoliberal para a educação Infantil e ganhe grátis dez passos para se tornar um professor reflexivo. Educação e Sociedade. v. 22, n. 74, abr. 2001.

CARR, Wilfrd e KEMMIS, Stephen. Teoria crítica de la enseñanza: la investigacionacciónen la formaión del professorado. Barcelona: Martinez Roca, 2001.

CASTRO, Cláudio e CARNOY, Martin. Como anda a reforma da educação na América Latina. Rio de Janeiro. Fundação Getúlio Vargas, 1997. 
CODO, Wanderley. Educação - Carinho e Trabalho. 3 ed. São Paulo: Vozes, 2002.

DEWEY, John. Como pensamos - como se relaciona o pensamento reflexivo com o processo educativo: uma reexposição. 3 ed. São Paulo: Companhia Editorial Nacional, 1933.

DUARTE, Newton. Vigotski e o "aprender a aprender": crítica às apropriações neoliberais e pós-modernas da teoria vigotskiana. 3 ed. Campinas, SP: Autores Associados, 2004.

ELLIOT, J. Recolando a pesquisa-ação em seu lugar próprio e original. In: GERALDI, Corinta M.G., FIORENTINI, Dario e PEREIRA, Elisabete M de A (orgs). Cartografias do trabalho docente: professor(a) pesquisador(a). Campinas: Mercado das LetrasALB, 1998.

FREITAS, Luís Carlos de. Neotecnicismo e formação do educador. In: ALVES, Nilda (org.). Formação de professores, pensar e fazer. São Paulo: Cortez, 1998.

FREITAS, Luís Carlos de. Uma pós-modernidade de Libertação: reconstruindo as esperanças. Campinas, SP: Autores Associados. 2005.

FRIGOTTO, Gaudêncio. A produtividade da escola improdutiva. São Paulo: Cortez, 1984.

FRIGOTTO, Gaudêncio. Educação e crise do capitalismo real. 2. ed. São Paulo:

Cortez, 1996.

GERALDI, Corinta Maria Grisola, FIORENTINI Dario; PEREIRA, Elisabete M. Aguiar (orgs.). Cartografias do trabalho docente: professor(a)-pesquisador(a). CampinasSP: ALB, 1998.

GIROUX. Henry. Os professores como intelectuais: rumo a uma pedagogia crítica. Porto Alegre: Artes Médicas, 1997.

GRAMSCI A. Os intelectuais e a organização da cultura. Rio de Janeiro: Civilização Brasileira, 1978.

GRAMSCI, Antônio. Cadernos do Cárcere. v. 1. Edição e tradução: Carlos Nelson Coutinnho. Rio de Janeiro: Civilização Brasileira, 1999.

KOSIK, Karel. Dialética do concreto. São Paulo: Paz e Terra, 1976.

LEWIN, Kurt. Psycologie dynamique. Les relations humanies. Paris: PUF, 1946.

LÖWY, Michael. As aventuras de Karl marx contra o Barão de Münchhausen: marxismo e positivismo na sociologia do conhecimento. 12 ed. São Paulo: Cortez, 1998.

MANACORDA, M. A. Marx e a pedagogia moderna. Tradução de Newton Ramos-deOliveira; revisão técnica de Paolo Nosella; prefácio de Demerval Saviani. 3. ed. São Paulo: Cortez, Autores Associados, 2000.

MARX, Karl e ENGELS, Friedrich. A ideologia alemã: teses sobre Feurbach. São Paulo: Moraes, 1984.

NóV0A. António. (org.). Os professores e sua formação. 3 ed. Lisboa: Dom Quixote, 1997. 
OLIVEIRA, Betty Antunes de. O trabalho educativo: reflexões sobre paradigmas e problemas do pensamento pedagógico brasileiro. Campinas-SP: Autores Associados,

1996.

PERRENOUD, P. et all ( org) Formando professores profissionais. Quais Estratégias? Quais Competências?. Porto Alegre: Artmed Editora, 2001.

RENAUT, A. O Indivíduo: reflexões acerca da filosofia do sujeito. Rio de Janeiro: Difel, 1998.

SACRISTÁN, J. Gimeno e GÓMEZ, A. L. Pérez. Compreender e transformar o ensino. 4 ed. Porto Alegre: Artmed, 1998.

SHON, Donald. Educando o profissional reflexivo. Porto Alegre: Artes Médicas, 2000. STENHOUSE, L. la investigación como base de la enseñaza. 2ed. Madri: Morata, 1987. STENHOUSE, L. Investigación y desarrollo del curriculum. 4 ed. Madrid: Morata, 2003.

VYGOTSKY, L. S. Pensamento e linguagem. 3. ed. São Paulo: Martins Fontes, 1991. ZARAGOZA, Jose Manuel Esteve. 0 mal-estar docente: a sala de aula e a saúde dos Professores. São Paulo: Edusc, 1999.

ZEICHNER, Kenneth M. A formação reflexiva de professores: idéias e práticas. Lisboa: Educa, 1993.

Recebido em julho de 2014

Aprovado dezembro de 2014

Kátia Augusta Curado Pinheiro Cordeiro da Silva é doutora em Educação pela Universidade Federal de Goiás (UFG) e professora da Universidade de Brasília (UnB), no Departamento de Administração e Planejamento (PAD) da Faculdade de Educação e no Programa de Pós-graduação em Educação. E-mail: katiacuradola unb.br 